\title{
Prognostic value of liver stiffness in HIV/ HCV-Coinfected patients with decompensated cirrhosis
}

\author{
Leire Pérez-Latorre ${ }^{1,2^{*}}$, Matilde Sánchez-Conde ${ }^{3}$, Pilar Miralles ${ }^{1,2}$, Juan Carlos López ${ }^{1,2}$, Francisco Parras ${ }^{1,2}$, \\ Francisco Tejerina ${ }^{1,2}$, Teresa Aldámiz-Echevarría ${ }^{1,2}$, Ana Carrero ${ }^{1,2}$, Cristina Díez ${ }^{1,2}$, Margarita Ramírez ${ }^{1,2}$, \\ Isabel Gutiérrez ${ }^{1,2}$, José María Bellón ${ }^{2}$, Rafael Bañares ${ }^{2,4,5,6}$ and Juan Berenguer ${ }^{1,2^{*}}$ [D
}

\begin{abstract}
Background: Little is known about the utility of transient elastography (TE) for assessing the prognosis of patients with decompensated cirrhosis (DC).

Methods: We analyzed HIV/HCV-coinfected patients with DC who underwent TE as part of their routine follow-up between 2006 and 2015. We also calculated the liver stiffness spleen diameter-to-platelet score (LSPS), FIB-4 index, albumin, MELD score, and Child-Pugh score. The primary outcome was death.

Results: The study population comprised 65 patients. After a median follow-up of 32 months after the first TE, 17 patients had received anti-HCV therapy and 31 patients had died. The highest area under the receiver operating characteristic curve (AUROC) value for prediction of death was observed with albumin (0.695), followed by ChildPugh score (0.648), both with $P$ values < .05. Lower AUROC values were observed with MELD score $(0.633)$, TE $(0$. 618), LSPS score (0.595), and FIB-4 (0.569), all with $P$ values $>$.05. In the univariate Cox regression analysis, albumin, FIB-4, Child-Pugh score, and MELD score, but not TE, were associated with death. In the multivariate analysis, albumin and Child-Pugh score were the only baseline variables associated with death.
\end{abstract}

Conclusions: Our results suggest that TE is not useful for assessing the prognosis of HIV-infected patients with decompensated HCV-related cirrhosis. Albumin concentration and Child-Pugh scores were the most consistent predictors of death in this population group.

Keywords: Transient elastography, Liver stiffness, Liver fibrosis, FibroScan, Coinfection, HIV infection, Hepatitis C

\section{Key points}

Transient elastography was not useful for assessment of the prognosis of HIV-infected patients with decompensated HCV-related cirrhosis. Serum albumin concentration and Child-Pugh score were the most consistent predictors of death in this population group.

\section{Background}

Chronic hepatitis $\mathrm{C}$ is more frequent and progresses more quickly in patients coinfected with human immunodeficiency virus (HIV) and hepatitis $\mathrm{C}$ virus (HCV)

\footnotetext{
*Correspondence: legor78@hotmail.com; jbb4@me.com

'Unidad de Enfermedades Infecciosas $/ \mathrm{NH}$, Hospital General Universitario

Gregorio Marañón, Doctor Esquerdo 46, 28007 Madrid, Spain

Full list of author information is available at the end of the article
}

than in patients infected solely by HCV. In addition, progression to liver cirrhosis and decompensated liver disease is faster among the former [1].

Assessment of prognosis is an essential element of the care of patients with HCV-related cirrhosis, as it provides useful information for clinical management and treatment decisions. It is important to bear in mind that cirrhosis is not a final, static, and irreversible disorder but a dynamic and potentially reversible condition that comprises two major stages, compensated and decompensated disease, with marked differences in prognosis between them $[2,3]$. Patients with compensated disease have a much longer median survival time than those with decompensated disease. Accordingly, measures of prognosis are also different for each stage; liver-related 
events such as hepatic decompensation or hepatocellular carcinoma are the most relevant outcomes in compensated cirrhosis, whereas death is the most relevant outcome in decompensated cirrhosis.

Portal pressure, which is usually determined using the hepatic venous pressure gradient (HVPG), is the most accurate predictor of liver-related events in patients with compensated cirrhosis [4]. In decompensated cirrhosis, survival is primarily related to liver function, which is usually assessed with scoring systems such as the ChildPugh score and the Model for End-Stage Liver Disease (MELD) score [5].

The aim of our study was to assess the utility of liver stiffness as a prognostic indicator in HIV/HCV-coinfected patients with decompensated cirrhosis. We chose this objective for two reasons: first, because transient elastography has been found to be an accurate method for the non-invasive assessment of HVPG in patients with compensated liver disease $[6,7]$ and is potentially useful for prediction of clinical outcomes in these patients [8-10]; and second, because HVPG, in addition to the MELD score, has been independently associated with survival in patients with decompensated cirrhosis [11].

\section{Methods}

\section{Study population and variables}

We studied all consecutive HIV/HCV-coinfected patients with decompensated cirrhosis who underwent transient elastography as part of their routine follow-up between 2006 (when this technique was routinely introduced for staging of liver fibrosis in HIV/HCV-coinfected patients in our institution) and 2015. We extracted all the data from hospital records. Liver decompensation was defined based on a history of ascites, hepatic encephalopathy, variceal bleeding, or non-obstructive jaundice.

Transient elastography was performed by trained operators using a FibroScan ${ }^{\ominus}$ device (EchoSens, Paris, France). A median of 10 successful acquisitions was considered the representative measurement of liver stiffness. We considered 10 acquisitions with a success rate $\geq 60 \%$ and an interquartile range $(\mathrm{IQR})<30 \%$ of the median value as representative measurements.

We also calculated the liver stiffness spleen diameter-toplatelet score (LSPS) (liver stiffness $\times$ spleen diameter in $\mathrm{cm} /$ platelet count in $\left.10^{9} / \mathrm{l}\right)$, as described elsewhere [12], and the FIB-4 index ([Age-years $\times$ AST-U/L]/ [Platelet count- $\left.\left.10^{9} / \mathrm{L} \times(\mathrm{ALT}-\mathrm{U} / \mathrm{L})^{1 / 2}\right]\right)$, a non-invasive fibrosis index derived from patients included in the APRICOT trial [13] that has better prognostic value than liver biopsy for prediction of liver-related events in HIV/HCV-coinfected patients with compensated liver disease [14]. The length of the spleen was calculated by measuring the larger diameter observed in the imaging tests (ultrasound or computed tomography) performed closest to the transient elastography study during the previous year. The Ethics Committee of Hospital General Universitario Gregorio Marañón approved the study.

\section{Statistical analysis}

Baseline was defined as the date of the first transient elastography determination after the diagnosis of decompensated cirrhosis. The length of the study was calculated for each patient from the date of the first transient elastography study to the last follow-up visit or death. The censoring date was June 30, 2015.

Categorical data were expressed as whole numbers and percentages and continuous variables as median and interquartile range (IQR). We used receiver operating characteristic (ROC) curves to determinate the ability of transient elastography to predict death.

Univariate Cox regression analysis was used to assess the association between transient elastography and other baseline covariates and death. As some patients were treated for $\mathrm{HCV}$ infection during follow-up, anti-HCV therapy was also included as a time-dependent variable in the univariate analysis. Multivariate Cox regression analysis was performed with the baseline variables that had attained a $P$ value $<.1$ in the univariate analysis.

\section{Results}

\section{Baseline characteristics}

The study population comprised $65 \mathrm{HIV} / \mathrm{HCV}$-coinfected patients with decompensated cirrhosis whose baseline characteristics, including the type of first hepatic decompensation, are shown in Table 1. The median date of first decompensation was August 2, 2008. The median time (IQR) from the first episode of decompensation to the first transient elastography was $6(0-33)$ months.

\section{Follow-up}

The median follow-up was 32 months. A total of 31 (48\%) patients died a median of 23 (13-51) months after the first transient elastography study; there were 19 liver-related deaths, 9 non-liver-related non-AIDS-related deaths, and 3 deaths of unknown cause. Four patients (6\%) were diagnosed with incident hepatocellular carcinoma, and 34 (52\%) patients had a new episode of liver decompensation that required hospitalization. No patients underwent liver transplantation.

During follow-up, 17 patients received anti-HCV therapy (simeprevir plus sofosbuvir [ $n=4]$, pegylated interferon plus ribavirin $[n=4]$, pegylated interferon plus ribavirin and telaprevir $[n=3]$, daclatasvir plus sofosbuvir $[n=3]$, and ledipasvir plus sofosbuvir $[n=3])$. Five patients achieved sustained viral response, 4 were nonresponders, and 8 were on treatment or had not reached the time for assessment of treatment response at the censoring date. 
Table 1 Baseline characteristics of 65 HIV/HCV-coinfected patients with decompensated cirrhosis categorized according to receipt of anti-HCV treatment during follow-up

\begin{tabular}{|c|c|c|c|}
\hline Baseline characteristic & $\begin{array}{l}\text { Patients who received HCV treatment } \\
(n=17)\end{array}$ & $\begin{array}{l}\text { Patients who did not receive HCV treatment } \\
(n=48)\end{array}$ & $\begin{array}{l}\text { All patients } \\
(N=65)\end{array}$ \\
\hline Male sex - n (\%) & $13(76)$ & $30(62)$ & $43(66)$ \\
\hline Age, years - median (IQR) & $46(42-49)$ & $46(43-50)$ & $46(43-50)$ \\
\hline HIV acquired by IDU - n (\%) & $12(70)$ & $45(94)$ & $57(88)$ \\
\hline Nadir, cells/mm³ - median (IQR) & $199(76-292)$ & $121(45-225)$ & $136(52-242)$ \\
\hline CD4+ cells/mm³ - median (IQR) & $294(216-482)$ & $258(160-423)$ & $293(165-424)$ \\
\hline CDC disease category C (\%) & $6(35)$ & $16(33)$ & $22(34)$ \\
\hline CART (\%) & $16(94)$ & $40(83)$ & $56(86)$ \\
\hline HIV-RNA < 50 copies/mL (\%) & $10(59)$ & $37(77)$ & $47(71)$ \\
\hline HBsAg-positive - n (\%) & $0(0)$ & $5(10)$ & $5(8)$ \\
\hline Alcohol intake > 50 g/day - n (\%) & $2(12)$ & $11(23)$ & $13(20)$ \\
\hline \multicolumn{4}{|l|}{ First decompensation - n (\%) } \\
\hline Ascites & $14(82)$ & $40(83)$ & $54(83)$ \\
\hline Variceal bleeding & $2(12)$ & $3(6)$ & $5(8)$ \\
\hline Hepatic encephalopathy & $0(0)$ & $5(10)$ & $5(8)$ \\
\hline Non-obstructive jaundice & $1(6)$ & $0(0)$ & $1(1)$ \\
\hline Hepatocellular carcinoma - median (IQR) & $1(6)$ & $2(4)$ & $3(4.6)$ \\
\hline \multicolumn{4}{|l|}{ Esophageal varices - n (\%) } \\
\hline Yes & $5(29)$ & $25(52)$ & $30(15)$ \\
\hline No & $8(47)$ & $9(19)$ & $17(2)$ \\
\hline Unknown & $4(23)$ & $14(29)$ & $18(28)$ \\
\hline Child-Pugh score - median (IQR) & $7(5-9)$ & $7(6-8)$ & $7(5-8)$ \\
\hline MELD score - median (IQR) & $11(7.5-15.5)$ & $11(7-14)$ & $11(7-14)$ \\
\hline Serum albumin, g/dL - median (IQR) & $3.5(2.4-4.2)$ & $3.0(2.5-3.7)$ & $3.1(2.5-3.9)$ \\
\hline FIB-4 value - median (IQR) & $6.5(3.1-13.5)$ & $6.4(4.2-10.6)$ & $6.4(3.8-10.6)$ \\
\hline Liver stiffness, kPa - median (IQR) & $50(34-70)$ & $48(35-63)$ & $48(35-64)$ \\
\hline LSPS - median (IQR) & $8.8(4.9-17.4)$ & $10.5(8-16.3)$ & $10.3(7.6-16.4)$ \\
\hline \multicolumn{4}{|l|}{ HCV genotype - median (IQR) } \\
\hline 1 & $12(70)$ & $26(54)$ & $38(58)$ \\
\hline 2 & $0(0)$ & $1(2)$ & $1(1.5)$ \\
\hline 3 & $3(18)$ & $9(19)$ & $12(18.5)$ \\
\hline 4 & $2(12)$ & $3(6)$ & $5(7.7)$ \\
\hline Unknown & $0(0)$ & $9(19)$ & $9(13.8)$ \\
\hline
\end{tabular}

Abbreviations: HCV hepatitis C virus, IQR interquartile range, HIV human immunodeficiency virus, CDC Centers for Disease Control and Prevention, $C A R T$ combination antiretroviral therapy, $H B s A g$ hepatitis B surface antigen, LSPS Liver stiffness $\mathrm{x}$ spleen diameter-to-platelet ratio

\section{Predictors of mortality}

The accuracy of liver stiffness and other baseline variables for the prediction of death are shown in Table 2. The highest area under the ROC curve (AUROC) value was observed with serum albumin concentration, followed by Child-Pugh score. Lower AUROC values were observed with MELD score, liver stiffness, LSPS score, and FIB-4 index.

The variables found to be associated with death by univariate Cox regression analysis were serum albumin,
FIB-4 index, MELD score, and Child-Pugh score. Transient elastography almost reached statistical significance, with an unadjusted hazard ratio (HR) (95\%CI) of 1.017 (0.998-1.037), $P=078$ (Table 3).

Child-Pugh and MELD scores are composite indexes whose formulas both include bilirubin concentration. Therefore, considering that serum albumin is included in the calculation of the Child-Pugh score and that both liver stiffness and FIB-4 are non-invasive markers of liver fibrosis, we avoided collinearity by constructing four 
Table 2 Accuracy of liver stiffness and other prognostic variables for the prediction of death assessed by ROC curves

\begin{tabular}{llll}
\hline Variable & Patients & AUROC $(95 \% \mathrm{CI})$ & $P$ Value \\
\hline Serum albumin & 64 & $0.695(0.566-0.825)$ & .007 \\
Child-Pugh score & 65 & $0.648(0.514-0.782)$ & .040 \\
MELD score & 65 & $0.633(0.494-0.772)$ & .065 \\
Liver stiffness & 65 & $0.618(0.482-0.755)$ & .100 \\
LSPS & 55 & $0.595(0.443-0.747)$ & .225 \\
FIB-4 & 64 & $0.569(0.428-0.710)$ & .343 \\
\hline
\end{tabular}

Abbreviations: $R O C$ receiver operating characteristic, $A U R O C$ area under receiver operating characteristic curve, $\mathrm{Cl}$ confidence interval, $M E L D$ model for end-stage liver disease, LSPS liver stiffness $\mathrm{x}$ spleen diameter-to-platelet ratio

Cox multivariate models with variables that achieved a $P$ value $<.1$ in the univariate analysis. As shown in Table 4, liver stiffness was not associated with death in any of the four models in which it was included. However, both serum albumin and Child-Pugh score were associated with death.

\section{Discussion}

In this study of $65 \mathrm{HIV} / \mathrm{HCV}$-coinfected patients with decompensated cirrhosis, of whom approximately half had died after a median follow-up of 32 months, we did not find an association between liver stiffness and death. Moreover, the LSPS score, an index that has been found to outperform transient elastography in the prediction of

Table 3 Univariate Cox regression analysis: variables associated with death in 65 HIV/HCV-coinfected patients with decompensated cirrhosis

\begin{tabular}{|c|c|c|c|}
\hline \multirow[t]{2}{*}{ Variable } & \multicolumn{3}{|c|}{ Univariate Analysis } \\
\hline & $\overline{\mathrm{HR}}$ & $95 \% \mathrm{Cl}$ & $P$ \\
\hline Sex (male vs female) & 0.887 & $0.417-1.887$ & .755 \\
\hline Age (per year) & 1.011 & $0.943-1.085$ & .749 \\
\hline Year of decompensation ( $\leq 2008$ vs $>2008$ ) & 1.238 & $0.563-2.724$ & .596 \\
\hline Alcohol intake > 50 g/day (yes vs no) & 1.232 & $0.522-2.905$ & .634 \\
\hline HBsAg (positive vs negative) & 1.210 & $0.366-4.005$ & .754 \\
\hline Nadir CD4+ (per cell/mm³) & 1.000 & $0.997-1.003$ & .920 \\
\hline Baseline CD4+ (per cell/mm³) & 0.999 & $0.997-1.001$ & .489 \\
\hline Esophageal varices (yes vs no) & 0.729 & $0.336-1.582$ & .424 \\
\hline Liver stiffness (per kPa) & 1.017 & $0.998-1.037$ & .078 \\
\hline Serum albumin (per g/dL) & 0.482 & $0.298-0.780$ & .003 \\
\hline FIB-4 (per unit) & 1.095 & $1.024-1.171$ & .008 \\
\hline Child-Pugh score (per unit) & 1.356 & $1.100-1.671$ & .004 \\
\hline MELD score (per unit) & 1.111 & $1.022-1.209$ & .014 \\
\hline LSPS (per unit) & 1.023 & $0.987-1.060$ & .220 \\
\hline Anti-HCV therapy ${ }^{a}$ (no vs yes) & 1.340 & $0.300-5.920$ & .695 \\
\hline
\end{tabular}

Abbreviations: $H I V$ human immunodeficiency virus, $H C V$ hepatitis $C$ virus, $H R$ hazard ratio, $C l$ confidence interval, $H B S A g$ hepatitis B surface antigen, MELD model for end-stage liver disease, LSPS liver stiffness $\times$ spleen diameter/platelet ratio

${ }^{\text {a C}}$ Computed as a time-dependent variable
Table 4 Multivariate Cox regression analysis: variables associated with overall death in 65 HIV/HCV-coinfected patients with decompensated cirrhosis

\begin{tabular}{llll}
\hline & aHR & $95 \% \mathrm{Cl}$ & $P$ \\
\hline Model 1 & & & \\
Liver stiffness (per kPa) & 1.013 & $0.991-1.034$ & .249 \\
Serum albumin (per g/dL) & 0.530 & $0.280-1.001$ & .050 \\
FIB-4 (per unit) & 1.027 & $0.932-1.131$ & .591 \\
MELD (per unit) & 0.986 & $0.872-1.115$ & .819 \\
Model 2 & & & \\
Liver stiffness (per kPa) & 1.013 & $0.999-1.033$ & .221 \\
FlB-4 (per unit) & 1.028 & $0.936-1.129$ & .568 \\
Child-Pugh score (per unit) & 1.276 & $0.975-1.672$ & .076 \\
Model 3 & & & \\
Liver stiffness (per kPa) & 1.013 & $0.992-1.035$ & .225 \\
Serum albumin (per g/dL) & 0.498 & $0.275-0.904$ & .022 \\
MELD (per unit) & 0.995 & $0.885-1.119$ & .936 \\
Model 4 & & & \\
Liver stiffness (per kPa) & 1.014 & $0.995-1.034$ & .152 \\
Child-Pugh score (per unit) & 1.338 & $1.080-1.656$ & .008 \\
\hline Abbrevatons: HV human immun
\end{tabular}

Abbreviations: HIV human immunodeficiency virus, $H C V$ hepatitis $C$ virus, aHR adjusted hazard ratio, $\mathrm{Cl}$ confidence interval, MELD model for end-stage liver disease, $\mathrm{kPa}$ kilopascal

portal hypertension and esophageal varices $[12,15,16]$, was not superior to transient elastography for prediction of death. These findings are discordant with the marked ability of transient elastography to predict clinical outcomes such as liver-related events $[8-10,17]$ and death $[8,18]$ in patients with compensated HCV-related cirrhosis with or without HIV coinfection.

The baseline variables associated with death in the univariate analysis included serum albumin, FIB-4 index, Child-Pugh score, and MELD score. In the multivariate analysis, serum albumin and Child-Pugh score were the baseline variables that better predicted death in patients with decompensated cirrhosis; these findings are consistent with those of a systematic review of predictors of death in patients with cirrhosis [5]. Seventeen of the 65 patients in our study received anti-HCV therapy during follow-up; 10 received only oral direct-acting antivirals (DAAs). As some patients died before they could receive anti-HCV therapy, we analyzed anti-HCV as a timedependent variable to avoid survivorship bias and found that it was not associated with survival. In a recent study, Foster et al. found that eradication of $\mathrm{HCV}$ with all oral DAAs was associated with short-term improvement in liver function in patients with HCV-related decompensated cirrhosis [19], although the long-term impact of eradicating $\mathrm{HCV}$ in this population group remains to be determined. Interestingly, the authors reported that serum albumin lower than $35 \mathrm{~g} / \mathrm{L}$ was one of 
the baseline factors associated with lower likelihood of benefiting from therapy, in addition to old age and low serum sodium.

Our findings are best understood in the light of the major differences in the pathophysiology of compensated and decompensated cirrhosis. In compensated cirrhosis, portal pressure is the main determinant of prognosis, depends mainly on intrahepatic factors [20], and can be accurately estimated using transient elastography [6, 21]. However, prognosis in decompensated cirrhosis is determined to a large extent by extrahepatic factors, including activation of neurohormonal mechanisms and persistent bacterial translocation that activates the immune system and aggravates systemic inflammation [22]. These mechanisms contribute to the clinical manifestations characteristic of this stage of cirrhosis, including bacterial infections, hemodynamic derangement, and organ inflammatory damage, all of which contribute significantly to death [22].

The main limitation of our study is its retrospective design. However, it must be emphasized that patients were followed up by the same physicians throughout the course of the disease, with frequent clinical and laboratory monitoring, as is common practice with HIVinfected patients. In addition, the complications of cirrhosis were managed and prevented following protocols based on contemporary clinical practice guidelines. Another limitation of the study is the absence of information about alcohol and drug use during follow-up. This limitation is relevant, because alcohol and drugs are known modifiers of the natural history of $\mathrm{HCV}$ related cirrhosis.

\section{Conclusions}

In conclusion, our results suggest that transient elastography is not useful for assessing the prognosis of HIVinfected patients with decompensated HCV-related cirrhosis. Serum albumin concentration and Child-Pugh scores were the most consistent predictors of death in this population group.

\section{Abbreviations}

AUROC: area under the ROC curve; DAAs: direct-acting antivirals; HCV: hepatitis C virus; HIV: human immunodeficiency virus; HVPG: hepatic venous pressure gradient; IQR: interquartile range; LSPS: Iiver stiffness spleen diameter-to-platelet score; MELD: model for end-stage liver disease; ROC: receiver operating characteristic
}

\section{Acknowledgements}

The authors thank Thomas O'Boyle for writing assistance during the preparation of the manuscript.

The FibroScan ${ }^{\oplus}$ device was donated by AbbVie Spain to "Grupo de Estudio del SIDA" (AIDS Study Group, GESIDA) of the "Sociedad Española de Enfermedades Infecciosas y Microbiología Clínica" (Spanish Society of Infectious Diseases and Clinical Microbiology, SEIMC).

\section{Funding}

This study was funded by a grant from Instituto de Salud Carlos III (ISC-III) Ref. PI14/01094 and by the RD16/0025/0017 project as part of the Plan
Nacional R + D + I and cofunded by ISCIII-Subdirección General de Evaluación and Fondo Europeo de Desarrollo Regional (FEDER).

LPL holds a grant from ISC-III Contrato Rio Hortega, Ref. CM15/00102.

$J B$ is supported by Programa de Intensificación de la Actividad Investigadora en el Sistema Nacional de Salud (I3SNS) (Refs. INT16/00100).

\section{Availability of data and materials}

The datasets used and/or analyzed during the current study available from the corresponding author on reasonable request.

\section{Authors' contributions}

LPL, MSC, RB, and JB made substantial contributions to conception, design, analysis and interpretation of data. $L P L, M S C, M R$, IG, and JMB made substantial contributions to acquisition of data. LPL, MSC, PM, JCL, FP, FT, $T A E, A C, C D, M R, I G, J M B$, RB, and JB have been involved in drafting the manuscript or revising it critically for important intellectual content. LPL, MSC, PM, JCL, FP, FT, TAE, AC, CD, MR, IG, JMB, RB, and JB gave final approval of the version to be published.

LPL, MSC, PM, JCL, FP, FT, TAE, AC, CD, MR, IG, JMB, RB, and JB agreed to be accountable for all aspects of the work in ensuring that questions related to the accuracy or integrity of any part of the work are appropriately investigated and resolved.

\section{Ethics approval and consent to participate}

The Ethics Committee of Hospital General Universitario Gregorio Marañón approved the study. The Committee waived the need for informed consent because the study was a retrospective chart review investigation that did not involve any risk to subjects, covered a prolonged period and because the requirement of individual consent would make the completion of the study impracticable.

\section{Consent for publication}

Not applicable

\section{Competing interests}

The authors declare that they have no competing interests.

\section{Publisher's Note}

Springer Nature remains neutral with regard to jurisdictional claims in published maps and institutional affiliations.

\section{Author details}

${ }^{1}$ Unidad de Enfermedades Infecciosas/VIH, Hospital General Universitario Gregorio Marañón, Doctor Esquerdo 46, 28007 Madrid, Spain. ${ }^{2}$ Instituto de Investigación Sanitaria Gregorio Marañón (liSGM), Madrid, Spain. ${ }^{3}$ Servicio de Enfermedades Infecciosas, Hospital Ramón y Cajal, Madrid, Spain. ${ }^{4}$ Servicio de Aparato Digestivo, Hospital General Universitario Gregorio Marañón, Madrid, Spain. ${ }^{5}$ Centro de Investigación Biomédica en Red en el Área Temática de Enfermedades Hepáticas y Digestivas (CIBEREHD), Madrid, Spain. ${ }^{6}$ Facultad de Medicina, Universidad Complutense de Madrid, Madrid, Spain.

Received: 8 August 2017 Accepted: 26 March 2018

Published online: 11 April 2018

References

1. Graham CS, Baden LR, Yu E, Mrus JM, Carnie J, Heeren T, Koziel MJ. Influence of human immunodeficiency virus infection on the course of hepatitis C virus infection: a meta-analysis. Clin Infect Dis. 2001;33(4):562-9.

2. Garcia-Tsao G, Friedman S, Iredale J, Pinzani M. Now there are many (stages) where before there was one: in search of a pathophysiological classification of cirrhosis. Hepatology. 2010;51(4):1445-9.

3. Zipprich A, Garcia-Tsao G, Rogowski S, Fleig WE, Seufferlein T, Dollinger MM. Prognostic indicators of survival in patients with compensated and decompensated cirrhosis. Liver Int. 2012;32(9):1407-14.

4. Ripoll C, Groszmann R, Garcia-Tsao G, Grace N, Burroughs A, Planas R, Escorsell A, Garcia-Pagan JC, Makuch R, Patch D, et al. Hepatic venous pressure gradient predicts clinical decompensation in patients with compensated cirrhosis. Gastroenterology. 2007;133(2):481-8.

5. D'Amico G, Garcia-Tsao G, Pagliaro L. Natural history and prognostic indicators of survival in cirrhosis: a systematic review of 118 studies. J Hepatol. 2006;44(1):217-31. 
6. Vizzutti F, Arena U, Romanelli RG, Rega L, Foschi M, Colagrande S, Petrarca A, Moscarella S, Belli G, Zignego AL, et al. Liver stiffness measurement predicts severe portal hypertension in patients with HCV-related cirrhosis. Hepatology. 2007:45(5):1290-7.

7. Sanchez-Conde M, Montes Ramirez ML, Bellon Cano JM, Caminoa A, Rodriguez FA, Garcia JG, Martin PM, Bernardino de la Serna I, Bernardo de Quiros JC, Arribas Lopez JR, et al. Impact of liver steatosis on the correlation between liver stiffness and fibrosis measured by transient elastography in patients coinfected with human immunodeficiency virus and hepatitis $C$ virus. J Viral Hepat. 2011;18(7):e278-83.

8. Pang JX, Zimmer S, Niu S, Crotty P, Tracey J, Pradhan F, Shaheen AA, Coffin CS, Heitman SJ, Kaplan GG, et al. Liver stiffness by transient elastography predicts liver-related complications and mortality in patients with chronic liver disease. PLoS One. 2014;9(4):e95776.

9. Robic MA, Procopet B, Metivier S, Peron JM, Selves J, Vinel JP, Bureau C Liver stiffness accurately predicts portal hypertension related complications in patients with chronic liver disease: a prospective study. J Hepatol. 2011; 55(5):1017-24

10. Perez-Latorre L, Rivero-Juarez A, Hontanon V, Diez C, Cuenca F, MartinCarbonero ML, Montes ML, Bellon JM, Aldamiz-Echevarria T, Carrero A, et al. Prognostic value of transient Elastography in human immunodeficiency virus-infected patients with chronic hepatitis C. Open Forum Infect Dis. 2016;3(4):ofw212.

11. Ripoll C, Banares R, Rincon D, Catalina MV, Lo lacono O, Salcedo M, Clemente G, Nunez O, Matilla A, Molinero LM. Influence of hepatic venous pressure gradient on the prediction of survival of patients with cirrhosis in the MELD era. Hepatology. 2005;42(4):793-801.

12. Kim BK, Han KH, Park JY, Ahn SH, Kim JK, Paik YH, Lee KS, Chon CY, Kim do Y. A liver stiffness measurement-based, noninvasive prediction model for high-risk esophageal varices in B-viral liver cirrhosis. Am J Gastroenterol. 2010;105(6):1382-90

13. Sterling RK, Lissen E, Clumeck N, Sola R, Correa MC, Montaner J, SS M, Torriani FJ, Dieterich DT, Thomas DL, et al. Development of a simple noninvasive index to predict significant fibrosis in patients with HIV/HCV coinfection. Hepatology. 2006;43(6):1317-25.

14. Berenguer J, Zamora FX, Aldamiz-Echevarria T, Von Wichmann MA, Crespo M, Lopez-Aldeguer J, Carrero A, Montes M, Quereda C, Tellez MJ, et al. Comparison of the prognostic value of liver biopsy and FIB-4 index in patients coinfected with HIV and hepatitis C virus. Clin Infect Dis. 2015;60(6):950-8.

15. Giannini E, Botta F, Borro P, Risso D, Romagnoli P, Fasoli A, Mele MR, Testa E, Mansi C, Savarino V, et al. Platelet count/spleen diameter ratio: proposal and validation of a non-invasive parameter to predict the presence of oesophageal varices in patients with liver cirrhosis. Gut. 2003;52(8):1200-5.

16. Berzigotti A, Seijo S, Arena U, Abraldes JG, Vizzutti F, Garcia-Pagan JC, Pinzani M, Bosch J. Elastography, spleen size, and platelet count identify portal hypertension in patients with compensated cirrhosis. Gastroenterology. 2013;144(1):102-11. e101

17. Kitson MT, Roberts SK, Colman JC, Paul E, Button P, Kemp W. Liver stiffness and the prediction of clinically significant portal hypertension and portal hypertensive complications. Scand J Gastroenterol. 2015;50(4):462-9.

18. Vergniol J, Foucher J, Terrebonne E, Bernard PH, le Bail B, Merrouche W, Couzigou P, de Ledinghen V. Noninvasive tests for fibrosis and liver stiffness predict 5-year outcomes of patients with chronic hepatitis C. Gastroenterology. 2011;140(7):1970-9. 1979 e1971-1973

19. Foster $\mathrm{GR}$, Irving $\mathrm{WL}$, Cheung $\mathrm{MC}$, Walker $\mathrm{AJ}$, Hudson $\mathrm{BE}$, Verma $\mathrm{S}$, McLauchlan J, Mutimer DJ, Brown A, Gelson WT, et al. Impact of direct acting antiviral therapy in patients with chronic hepatitis $C$ and decompensated cirrhosis. J Hepatol. 2016;64(6):1224-31.

20. Abraldes JG, Garcia-Pagan JC, Bosch J. Functional component of portal hypertension. Gastroenterol Hepatol. 2004;27(6):377-87.

21. Sanchez-Conde M, Miralles P, Bellon JM, Rincon D, Ramirez M, Gutierrez I, Ripoll C, Lopez JC, Cosin J, Clemente G, et al. Use of transient elastography (FibroScan(R)) for the noninvasive assessment of portal hypertension in HIV/ HCV-coinfected patients. J Viral Hepat. 2011;18(10):685-91.

22. Albillos $\mathrm{A}$, Lario M, Alvarez-Mon M. Cirrhosis-associated immune dysfunction: distinctive features and clinical relevance. J Hepatol. 2014;61(6):1385-96.

\section{Submit your next manuscript to BioMed Central and we will help you at every step:}

- We accept pre-submission inquiries

- Our selector tool helps you to find the most relevant journal

- We provide round the clock customer support

- Convenient online submission

- Thorough peer review

- Inclusion in PubMed and all major indexing services

- Maximum visibility for your research

Submit your manuscript at www.biomedcentral.com/submit
Biomed Central 